\title{
Facebook Sharenting in Mothers of Young Children: The Risks Are Worth It but Only for Some
}

\author{
Raluca A. Briazu', Caroline Floccia ${ }^{2}$, and Yaniv Hanoch ${ }^{3}$ \\ ${ }^{1}$ School of Psychology and Clinical Language Sciences, University of Reading \\ ${ }^{2}$ School of Psychology, University of Plymouth \\ ${ }^{3}$ Southampton Business School, University of Southampton
}

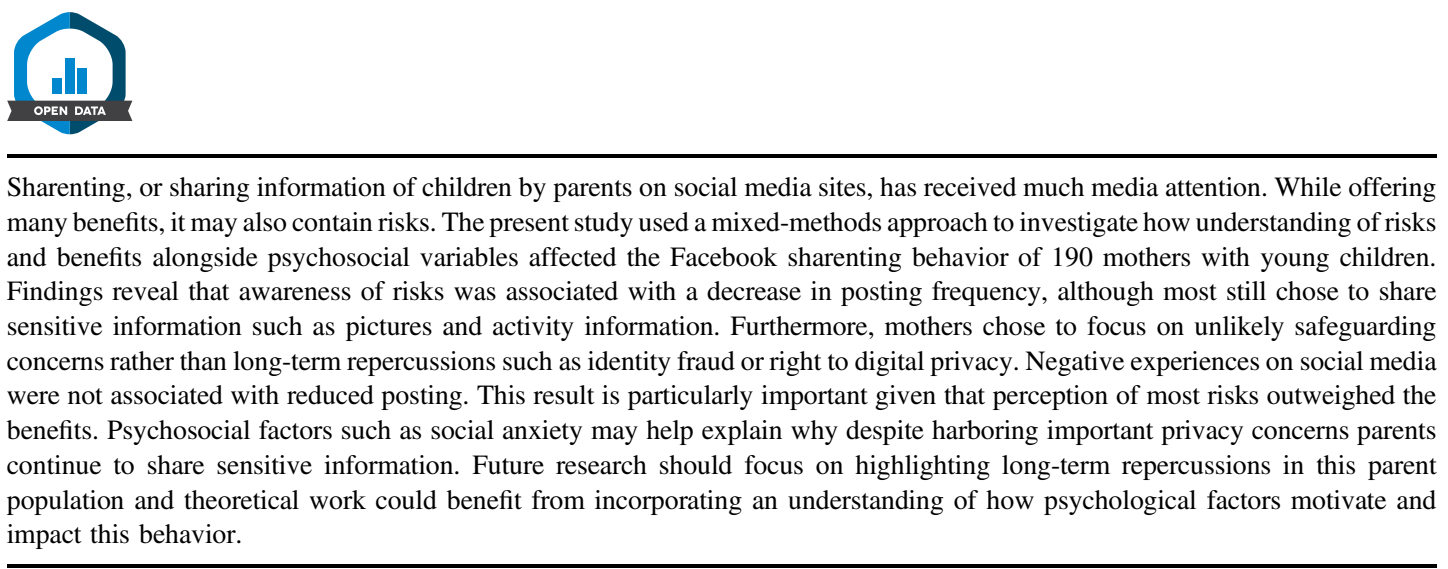

Keywords: Facebook, mothers, risk-taking, sharenting, social media

Supplemental materials: https://doi.org/10.1037/tmb0000051.supp

According to the Office for National Statistics (Office for National Statistics, 2019a), 91\% of U.K. adults aged 25-34 are actively using social networking sites such as Facebook and Twitter. This segment of the population is also most likely to have young children (Office for National Statistics, 2018). One common practice among parents using social media is "sharenting", namely, sharing detailed information about their children on social media (Collins, n.d.). Sharenting offers parents a range of benefits, such as providing social support and enabling connections to others (Wagner \& Gasche, 2018). Sharenting can be done safely, and parents are at times actively encouraged to share details about their family life, such as during the recent pandemic (Bessant et al., 2020). However, the practice can have detrimental consequences for the children involved.

Researchers have pointed out that sharing information about one's children could be abused by criminals (Plunkett, 2019), for example by sharing information about a child's home address and birthday, parents risk future identity fraud. A report by Barclays Bank suggests that sharenting could account for two-thirds of identity fraud by 2030 (Coughlan, 2018). Even sharing information about very young children can lead to future identity fraud given the ability to store data until the child reaches adulthood. Data brokers, who collect and sell information to companies for marketing and professional purposes, are known to automatically gather data and
Action Editor: Danielle S. McNamara was the action editor for this article.

ORCID Ids: Raluca A. Briazu (iD https://orcid.org/0000-0002-7159-1261; Yaniv Hanoch (iD https://orcid.org/0000-0001-9453-4588.

Disclosures: We have no known conflict of interest to disclose.

Data Availability: The data that support the findings of this study are openly available in the Open Science Framework (OSF) repository at https:// doi.org/10.17605/OSF.IO/HCMS7 (Briazu, 2021).

Open Science Disclosures:

II The data are available at https://doi.org/10.17605/OSF.IO/HCMS7
Open Access License: This work is licensed under a Creative Commons Attribution-NonCommercial-NoDerivatives 4.0 International License (CC-BY-NC-ND). This license permits copying and redistributing the work in any medium or format for noncommercial use provided the original authors and source are credited and a link to the license is included in attribution. No derivative works are permitted under this license.

Contact Information: Correspondence concerning this article should be addressed to Raluca A. Briazu, School of Psychology and Clinical Language Sciences, University of Reading, Office 1S02, Harry Pitt Building, Earley Gate, Reading, RG6 7BE, United Kingdom. Email: r.briazu@reading.a.uk 
compile detailed files on children. These files can be continuously accessed throughout a child's life (Minkus et al., 2015). Such data are in demand given the booming children's merchandize market. These data are also easy to obtain because most children already have a digital footprint by the age of two (Magid, 2010). Scholars are also concerned that sharenting affects a child's right to digital privacy (Davidson-Wall, 2018). These circumstances are especially problematic when parents create a negative digital footprint for their children. Take for instance the controversial case of a family sharing a Christmas card photo featuring the mother and the two daughters gagged with green duct tape and bound with Christmas lights with the father alongside his toddler boy holding a sign saying, "Peace on Earth" (BBC News, 2015). The post went viral and attracted a lot of negative attention. Although the post was deleted shortly after it was posted, 6 years on the image can easily be traced online. The children in this photo probably had little say in how the picture was set-up or shared; yet they cannot opt-out of the digital footprint their family established for them. This issue is further magnified by the possibility of retrospectively tagging children in pictures using platform-based facial recognition software (Barnes \& Potter, 2021).

Older children report they value parents sharing content that portrays them in a positive light. They object however to content they deem as embarrassing such as naked baby pictures or stories of them getting in trouble. Importantly, older children think parents should ask for permission more than their parents think they should (Moser et al., 2017). Very young children cannot express their privacy concerns and preferences in a similar manner. Therefore, parents hold the absolute power over young children's right to digital privacy (Steinberg, 2016). These circumstances can create a conflict of interest especially when children's interest in privacy is separate from that of their parents (Shmueli \& Blecher-Prigat, 2010). As they grow older young children may discover that an archive of their childhood is available online and may become emotionally harmed if they deem this content as embarrassing (Nottingham, 2019). This could lead to a violation of trust and threaten the parent-child relationship (Siibak \& Traks, 2019). Therefore, the negative effects of sharenting are not necessarily immediate as problems might also occur in the future. Taking the above into account, we consider sharenting of young children to be risky.

As digital literacy strongly predicts safe online behavior (Park, 2013), educational campaigns have focused on informing parents about the risks and safe sharenting behaviors (National Society for Prevention of Cruelty to Children, 2015; Steinberg, 2019). However, there is limited empirical evidence as to whether parents' awareness of risks reduces sharenting behavior. For example, it is possible for users to be concerned about privacy yet do little to protect their data, a phenomenon referred to as the privacy paradox (Barth \& De Jong, 2017). Parents, likewise, could be cognizant of the risks associated with sharenting yet fail to engage in protective behavior. The few studies that have been undertaken on this topic do indeed show that mothers from the United States (U.S.; Kumar \& Schoenebeck, 2015) and Australia (Chalklen \& Anderson, 2017) are aware of sharenting risks yet choose to engage in it anyway. There is however limited information about the sharenting behavior of parents from the United Kingdom (U.K.). This gap is notable given that different cultural contexts can influence social media use. For example, Vasalou et al. (2010) found that participants from the U.K. spend more hours on Facebook when compared to participants from the U.S.
There is also a lack of understanding concerning the psychosocial factors that drive sharenting behavior. Location sharing, a behavior sometimes involved in sharenting can be predicted by impulsivity (Hadlington, 2017). However, we are yet to understand if sharenting can also be linked to factors such as feelings of loneliness or need to belong, factors known to affect other types of risky behaviors (Wegmann \& Brand, 2019). Understanding the multidimensional nature of sharenting decisions is important as it could help the development of more suitable programs to encourage safer sharenting behaviors. Recent research exploring sharenting behavior of U.K. parents on Instagram reported that peer influence can be a strong predictor of sharenting (Ranzini et al., 2020). Facebook, however, is still the most widely used social media platform (YouGov, 2020). Therefore, investigating antecedents of sharenting on this social media platform is necessary.

Aside from psychosocial factors, people's predisposition to engage in risky behavior has been found to be based on a tradeoff between perceived benefits and risks (Weber et al., 2002). For example, adolescents' willingness to disclose sensitive information online is predicted by their perceived benefits (Youn, 2005). As previously mentioned, sharenting can also result in many benefits. Thus, one might expect sharenting decisions to be based on a riskbenefit analysis. Yet, no study has examined this issue directly, especially in the context of Facebook sharenting by mothers.

Given this background, the present study was specifically designed to evaluate how understanding of risks and benefits alongside psychosocial variables drive Facebook sharenting behavior in mothers of young children. Although sharenting is not gender specific, our research focuses on mothers as they tend to post information about their children more frequently than fathers (Ammari et al., 2015; Duggan et al., 2015). We also wanted to particularly focus on mothers of young children as this population is characterized by factors that are likely to influence sharenting behavior. For example, parents of young children are likely to have engaged with social media prior to becoming parents thus gaining a rich digital experience before sharenting. Prior experience has also been shown to impact the assessments of risks and benefits associated with sharing information online that in turn affects privacy protection behavior (Debatin et al., 2009). Some also suggest (though data are limited) that growing up in a context where social media plays a significant role in relationships and interactions might make one more permissive of sharing information about their own children (Brosch, 2016). Additionally, mothers of young children experience lifestyle changes that may lead to social isolation and therefore compound the use of social media. Gibson and Hanson (2013), for example, found that mothers of babies and toddlers use social networking sites to seek advice to improve their confidence and as a means to achieve identity preservation by maintaining connections and nonmothering hobbies.

Our research, was, therefore designed to provide important insights about the factors that drive sharenting behaviors in this population. To do so, we asked the following research questions: (a). Is previous negative experience on social media associated with any sharenting behaviors? (b). What sharenting risks are mothers of young children aware of and is this knowledge associated with their posting activity? (c). How do mothers balance risks with benefits? (d). What psychosocial factors are associated with mothers' perception of sharenting risks and benefits? The study was designed using a mixed-methods approach with the aim of increasing the 
comprehensiveness of findings by allowing us to further understand statistical data with the use of qualitative information. This is the first study to use a mixed-methods approach to investigate sharenting behavior of mothers living in the U.K.

Given that prior negative experiences increase privacy concerns and perceived risks (Bansal \& Gefen, 2010; Yang \& Liu, 2014), we hypothesize that prior negative experiences would be associated with a decrease in sharenting behavior. Next, given that digital literacy has been shown to strongly predict safe online behavior (Park, 2013) we hypothesize that mothers aware of more risks will be less likely to engage in sharenting behavior. We had no a priori hypothesis regarding the last two research questions given their exploratory nature.

\section{Method}

\section{Participants}

Following approval from the Internal Review Board for Ethics, participants were recruited through social media adverts and by contacting members of the University's Babylab. A total of 190 mothers participated. Mothers' youngest child was aged between 0 and 3 with $53.7 \%$ having a 1-year old. Most participants were aged between 25 and 34 years $(62.6 \%)$ and had one child (52.6\%). Most had an undergraduate or postgraduate degree $(68.9 \%)$ and were in full-time or part-time employment (75.3\%). Similar to our sample, according to the Office for National Statistics (Office for National Statistics, 2019b), almost half of all registered U.K. births are to mothers aged 25-34, most of which either have one or two children.

A post hoc power analysis was conducted using GPower (Erdfelder et al., 1996). The effect size used for this assessment was 0.25 based on previous research on sharenting in the U.K. (Ranzini et al., 2020). The analysis revealed that statistical power for this study was between 0.92 and 0.94 depending on the analysis run, thus there was more than adequate power to observe a small to moderate effect size.

\section{Materials and Procedure}

\section{Social Media Use}

Multiple-choice items were used to measure participants' social media use, including the number of friends on Facebook, relationships with Facebook friends, posting frequency, knowledge about security settings, type of information being shared, and use of other social media sites. All items used in this part of the questionnaire are provided in Appendix A.

\section{Previous Experiences}

Two open-ended questions asked participants to describe any negative experiences they or a close relative/friend had experienced on Facebook. An additional question asked whether participants had ever regretted posting information on Facebook.

\section{Perceived Risks and Benefits}

We developed this scale based on the Domain-Specific RiskTaking Scale (Weber et al., 2002). Ten items rated on a 7-point scale asked about the perceived risks $(1=$ very low risk to $7=$ very high risk; 5 items, $\alpha=.88$ ) and benefits ( 5 items, $\alpha=.88 ; 1=$ very low benefit to $7=$ very high benefit) of sharing different types of information with either family, friends, or strangers (questionnaires included in Appendix B).

One open-ended question asked about specific risks. This was phrased as: "In your opinion what could be the risks of sharing information or pictures of children on social media?". An equivalent question was asked to ascertain specific benefits. Participants were asked to provide a written response to complete the questionnaire.

\section{Psychosocial Aspects of Facebook Use Scale (Bodroža \& Jovanović, 2016)}

The Psychosocial Aspects of Facebook Use scale (PSAFU) measures psychological aspects of Facebook use on five subscales with items rated on a 5-point rating scale. Compensatory Facebook use (13 items, $\alpha=.92$ ) and Facebook addiction ( 8 items, $\alpha=.88$ ) subscales measure potentially maladaptive aspects of Facebook use, which can indicate internet addiction. The Self-Presentation subscale ( 8 items, $\alpha=.92$ ) assesses the desire to present one's ideal self and has been linked to social anxiety. The Virtual Self subscale ( 5 items, $\alpha=.76$ ) assesses the representation of a person's real self and can indicate whether Facebook has become an important aspect of one's personality. The Socialization subscale ( 9 items, $\alpha=.88$ ) measures active striving to acquaint new friends or partners through Facebook and has been linked to higher sensation seeking.

\section{Analysis}

Answers to multiple-choice questions were analyzed using descriptive frequencies. Open-ended questions were analyzed using summative content analysis as responses were in single-word or short sentence formats (Hickey \& Kipping, 1996). Initially, we identified a small number of categories based on previous literature (Wagner \& Gasche, 2018), which were revised or further developed through examination of the data. One of the authors independently identified key categories from the responses. These were subsequently sorted into subcategories to develop an initial coding frame and a second researcher used this to independently analyze the data. Across openended questions, average interrater agreement rate was $83.8 \%$ and Cohen's Kappa ranged from .44 (moderate agreement) to 1 (perfect agreement; Sim \& Wright, 2005). See Tables 1 and 3, for Cohen's Kappa values for each subtheme. Discrepancies were discussed and where appropriate the coding frame was adjusted either by adding categories or adjusting definitions. Finally, categories were quantified using frequency counts. The data that support the findings of this study are openly available in the Open Science Framework (OSF) repository at https://doi.org/10.17605/OSF.IO/HCMS7 (Briazu, 2021).

\section{Results}

\section{Facebook Use}

All participants had a Facebook account, with $65.1 \%$ having between 101 and 500 friends and $24.8 \%$ having fewer than 100 friends. All but two participants were aware of their privacy setting, and most had this set to "Friends" (82.1\%), with only $4.2 \%$ set to "Custom Audience." When asked about their friends' privacy setting 55.8\% stated that these also had a "Friends" privacy setting, however, $36.8 \%$ did not know. The majority $(72.1 \%)$ knew all their 
Table 1

Content Analysis Findings on Open Questions About Risks, Including Categories and Subcategories, Frequency Counts and Examples

\begin{tabular}{|c|c|c|c|}
\hline Categories and subcategories & $\%$ & Example & Cohen's Kappa \\
\hline \multicolumn{4}{|l|}{ Digital ownership } \\
\hline Lack of control & 26.8 & "Lose control over the images" & 0.65 \\
\hline Digital kidnapping & 5.8 & "People taking your photos to use for themselves." & 0.51 \\
\hline Sharing beyond intended group & 32.1 & "Shared with people you do not know" & 0.86 \\
\hline \multicolumn{4}{|l|}{ Safeguarding issues } \\
\hline Kidnapping/child trafficking & 13.7 & $\begin{array}{l}\text { "Posting details such as school/regular activities increases risk of selective } \\
\text { abduction" }\end{array}$ & 0.57 \\
\hline Sexual abuse/child grooming & 21.1 & "Could give predators information to be able to get close to the child." & 0.44 \\
\hline Cyberbullying & 1.6 & "Unwanted comments", "Cyberbullying" & 0.56 \\
\hline Stalking/harassment & 3.2 & "It puts them at risk of unwanted attention" & 0.88 \\
\hline Nonspecific safeguarding issues & 11.1 & "A very determined nutter could track them down", "Inappropriate use" & 0.68 \\
\hline Fraud & 5.3 & "Phishing, fraud" & 0.53 \\
\hline Concerns about privacy & 34.2 & $\begin{array}{l}\text { "Information about the whereabouts of the children, where they go, what they do, } \\
\text { what they like, what they look like, what they are called, where they live. All } \\
\text { possible information that can be used negatively." }\end{array}$ & 0.85 \\
\hline \multicolumn{4}{|c|}{ P } \\
\hline Concerns about consent & 3.7 & $\begin{array}{l}\text { "I have put a couple of pictures of my child on FB (custom audience) but never with } \\
\text { his face showing/identifiable as I feel it is not my choice to make" }\end{array}$ & 0.83 \\
\hline Negative impact in future & 4.2 & $\begin{array}{l}\text { "Entities could data harvest your child's life, they would be able to predict intimate } \\
\text { aspects of your child's personality because they will know intimate details of their } \\
\text { upbringing." }\end{array}$ & 0.70 \\
\hline Diminished risk impact & 8.4 & $\begin{array}{l}\text { "Identifying location of where my child frequents. However, these are normally } \\
\text { popular child-friendly places where many children are daily. Thus, low risk in my } \\
\text { opinion." }\end{array}$ & 0.93 \\
\hline No concerns expressed & 2.1 & "I don't see many issues" & 0.77 \\
\hline
\end{tabular}

Facebook friends face to face, but none were friends with all of them outside of Facebook. For most $(56.8 \%)$, less than half of their Facebook Friends were persons they communicated with outside of Facebook and for the majority (83.2\%), relatives made up less than half of friends in the list.

The majority stated that they posted between one and five times per week $(58.4 \%)$, and $32.1 \%$ stated they did not post at all. Most $(89.5 \%)$ posted pictures of their child on Facebook and $76.3 \%$ stated that such pictures were usually acknowledged either more or much more compared to other photos. In terms of the type of information shared, most shared information about special days $(72.7 \%)$ or social activities (52.6\%). Parents did share information about health $(6.7 \%)$ or educational issues $(5.2 \%)$ but to a far lesser extent. Parents who posted on Facebook more frequently were also more likely to share more types of information about their children $(r=.50, p<$ $.001) .{ }^{1}$ Just over half of participants $(51.9 \%)$ who shared information about their child on Facebook also shared information on platforms such Snapchat, Instagram, or Twitter.

\section{Previous Negative Experiences}

Close to $17 \%$ of mothers reported having a negative experience on Facebook, and a similar percentage (18.4\%) regretted sharing photos, location, or status updates. The most frequent negative experience mentioned was unwanted attention, which ranged from being contacted by advertisement companies to being contacted by strangers or previous acquaintances. Also mentioned was being involved in arguments, receiving offensive comments, being exposed to offensive materials, or being trolled. Five participants mentioned a negative experience involving child-related posts, most of these focused on family members or friends sharing photos or information about the child without consent, for example: "Family member took the pics and posted then on other sites without my permission." Some also mentioned invasions of privacy despite measures taken against this, for example: "Someone who was no longer a Facebook friend was able to 'stalk' and find out that I had a baby daughter even though I thought all my privacy settings would prevent it."

More mothers $(26.3 \%)$ reported knowing friends or family who had had a very similar negative experience on Facebook.

There was no difference in posting frequency between those who had had a negative experience on Facebook and those who had not, $t(196)=1.10, p=.275$. Similarly, there was no difference in posting frequency between those who knew a friend or relative, who have had a negative experience on Facebook and those who did not, $t(185)=$ $1.02, p=.308$. Regretting past Facebook activity also did not make a difference in terms of posting frequency $t(185)=.64, p=.525$. Fisher's exact tests indicated that having had a negative experience ( $p=1.00)$ or knowing someone that had a negative experience on Facebook $(p=.607)$ did not make a difference as to whether one decided to post a picture of their children or not. This was also the case when looking at whether regretting previous activity of Facebook was associated with posting pictures of children online $(p=.772)$.

\section{Perceived Risks}

When evaluating risk on a scale ranging from 1 to 7 , posting pictures $(M=4.46, S D=1.71)$ was regarded as riskier than sharing activity information $(M=4.07, S D=1.50), t(188)=-5.14, p<.001$. Sharing with family members was judged as less risky $(M=3.05, S D=1.61)$ than sharing with friends $(M=3.64, S D=1.62)$, while sharing with strangers was the riskiest $(M=6.21, S D=1.22)$.

\footnotetext{
${ }^{1}$ All correlations reported in this article were subject to Bonferonni correction for multiple comparisons.
} 
All content analysis findings about risks are presented in Table 1. We calculated the total number of different risks mentioned by each individual and examined the relationship with posting frequency. On average participants mentioned 1.65 different risks $(S D=.91$, Range $=0-6)$. Participants who mentioned more risks posted slightly the less frequently on Facebook $(r=-.259, p<.001)$.

There was no difference in number of risks mentioned between participants who had a previous negative experience on Facebook and those who did not, $t(186)=-.55, p=.584$, with similar results emerging when comparing participants who knew friends who had a negative experience versus those who did not, $t(185)=-.20, p=$ .840. Those who regretted posting information on Facebook did not differ from those who did not in number of risks mentioned, $t(185)=$ $-.66, p=.513$.

Parents who did not post pictures of their children on Facebook mentioned significantly more risks $(M=2.15, S D=1.18)$ compared to parents who did post pictures $(M=1.59, S D=.85), t(188)=$ $-2.66, p=.008$.

Each theme identified when performing content analysis on the open-ended questions regarding risks is discussed below.

Digital Ownership. Most participants identified digital ownership as a major concern (58.9\%). Participants were particularly concerned about information being shared with strangers and some were aware that this might be an issue even when attempting to control who the content is shared with. Similarly, participants also raised concerns about the lack of control over distribution and use of the information posted online. Only a small number of participants expressed concern about others using information as their own.

Safeguarding the Children. In total $41.6 \%$ of participants mentioned at least one subcategory related to safeguarding issues. While some participants referred to a general concern that children could be targeted in a variety of ways, others were more specific. As shown in Table 1, sexual abuse and child grooming were the most widely mentioned, with kidnapping and child trafficking also being a concern. Cyberbullying and stalking were mentioned but to a lesser extent.

Concerns About Privacy. As shown in Table 1, roughly a third of participants expressed concerns that others might be able to track their activities or location and harvest personal data. These concerns focused on identifying a child's location and were often linked to safeguarding issues.

Fraud. A limited number of participants mentioned risks that are not focused on the child themselves, but rather on other criminal consequences. These participants mentioned phishing and identity theft.

Future Risks. Only a few participants were concerned with how the sharing of information might affect their children in the future. Most of these concerns were general, although some pinpointed more exact concerns (see Table 1). Some also noted concerns regarding consent from the child.

Diminished Risk Impact. Responses that were assigned to this category acknowledged that risks exist but also noted this was not necessarily something to be concerned about; others mentioned risks but acknowledged that minimizing the risk was something fully within their control. Only $2.06 \%$ stated that they believed there were no risks involved.

\section{Perceived Benefits}

Posting pictures were regarded as more beneficial $(M=2.76$, $S D=1.54)$ than sharing information about activities $(M=2.42$, $S D=1.43), t(233)=5.01, p<.001$. The benefit of sharing pictures of children with family members was regarded as the most beneficial $(M=4.27, S D=1.87)$, followed by sharing pictures with friends $(M=3.30, S D=1.62)$, and finally with strangers $(M=1.30$, $S D=1.02)$. To analyze how participants rated risks in comparison to benefits we ran a series of paired $t$-tests, results are presented in Table 2. Most risks were rated significantly higher than the equivalent benefit; benefits, however, outweighed risks when considering sharing information and photos with family. There were no differences between how participants rated the risks and benefits of sharing information with friends.

Five main categories emerged when analyzing the open-ended responses regarding perceived benefits, all are identified in Table 3 and discussed below. On average participants mentioned 1.18 different benefits $(S D=.64$, Range $=0-4)$.

Building Connections. Most participants mentioned that the benefit of sharing photos and information about their children online is being able to keep in touch with family and/or friends by updating them about the child's development, which was mentioned by $68.9 \%$ of participants as the only benefit. A small number of parents mentioned connecting with other parents as a way to achieve a sense of community.

Practical Benefits. Some participants mentioned the practical parental benefits Facebook offers. Asking for parenting advice was the most frequent subtheme. Some mentioned posting pictures and information in order to acquire general advice while others included medical advice. The convenience of sharing information about their child through this mode was also mentioned. Four participants indicated that social media could serve as a free storage facility and two participants mentioned possible financial benefits.

Emotional Benefits. Participants denoted that sharing information is beneficial because it enables them to express positive emotions, such pride and joy of their children, while others mentioned that it can afford joy to others. Participants also referred to

Table 2

Paired Sample t-Tests Results Comparing Perceived Risks With Benefits

\begin{tabular}{lrrrr}
\hline \multicolumn{1}{c}{ Pairs } & $M(S D)$ & \multicolumn{1}{c}{$t$} & $d f$ & $p$ value \\
\hline Risk posting picture-Benefit posting pictures & $1.30(2.44)$ & 7.33 & 187 & $<.001$ \\
Risk sharing activity info-Benefit sharing activity info & $2.04(2.61)$ & 10.73 & 188 & $<.001$ \\
Risk posting pictures family_Benefit posting pictures family & $-1.22(2.88)$ & -5.82 & 188 & $<.001$ \\
Risk posting pictures friends-Benefit posting pictures friends & $.34(2.66)$ & 1.73 & 187 & .085 \\
Risk posting pictures strangers-Benefit posting pictures strangers & $4.90(1.64)$ & 41.25 & 188 & $<.001$ \\
\hline
\end{tabular}


Table 3

Content Analysis Findings on Open Questions About Benefits, Including Category and Subcategories, Frequency Counts and Examples

\begin{tabular}{|c|c|c|c|}
\hline Categories and subcategories & $\%$ & Example & Cohen's Kappa \\
\hline \multicolumn{4}{|l|}{ Building connections } \\
\hline Keeping family and friends up to date & 83.7 & $\begin{array}{l}\text { "Keeps the relationship open between friends and family who are not local or } \\
\text { who are not seen as often" }\end{array}$ & 0.73 \\
\hline Achieving a sense of community & 4.2 & "Social inclusion of isolated parents" & 0.56 \\
\hline \multicolumn{4}{|l|}{ Practical benefits } \\
\hline Asking for advice & 5.8 & $\begin{array}{l}\text { "My youngest is dairy intolerant so by me sharing I get help and advice about } \\
\text { this" }\end{array}$ & 0.65 \\
\hline Convenience & 5.8 & $\begin{array}{l}\text { "It is the easiest way I can share pictures and information about how she is } \\
\text { growing up" }\end{array}$ & 0.65 \\
\hline Archiving of information & 2.1 & "a good place to store pictures as long as only certain people can see them" & 1 \\
\hline Financial or material gains & 1.1 & "My daughter models for companies so it brings her an income" & 0.57 \\
\hline \multicolumn{4}{|l|}{ Emotional benefits } \\
\hline Enabling positive emotions & 5.3 & $\begin{array}{l}\text { "I enjoy showing family and friends my daughters progress, it took us a long } \\
\text { time to conceive her and I am so proud to be a mummy I like to show } \\
\text { everyone" }\end{array}$ & 0.51 \\
\hline Emotional support & 2.1 & "Receiving likeminded support from fellow parents" & 0.45 \\
\hline Helping others & 7.4 & $\begin{array}{l}\text { "It engages other parents who haven't tried groups or activities, shares } \\
\text { experiences among my friends who have a different life experience to us" }\end{array}$ & 0.77 \\
\hline No benefit & 5.8 & "I don't think there are any" & 0.88 \\
\hline
\end{tabular}

social media as a way of achieving comfort and support in times of turmoil and thus achieving emotional support.

Helping Others. A few participants also mentioned that sharing information can be beneficial to others, these parents mostly referred to sharing activity information, but also mentioned sharing parenting experiences.

No Benefits. Eleven participants noted that there were no benefits to sharing information and pictures about their children online. Nevertheless, these participants still had a Facebook account and eight stated they had shared photos or information about their child's special events. Interestingly, eight parents (4.1\%) acknowledged some benefits but also highlighted safer ways of sharing information. Most focused on the use of other facilities that can afford secure sharing of data such as WhatsApp. Other strategies such as sharing photos through email or through cloud storage were also mentioned.

\section{Relationship With Psychosocial Factors}

Risks. Participants who scored higher on the PSAFU Virtual Self subscale (those who felt that Facebook is a realistic representation of oneself) were slightly less likely to think that posting pictures $(r=-.20, p=.008)$ or sharing activity online was risky $(r=$ $-.27, p<.001)$. These participants were also marginally less likely to regard sharing pictures with friends $(r=-.24, p<.001)$ or family
( $r=-.26, p<.001)$ as risky. Those scoring high on the Socialization subscale (namely participants who use FB to acquaint new friends) were slightly less likely to perceive sharing pictures with strangers as risky $(r=-.21, p=.005)$. Compensatory Facebook use (describing the use of Facebook as a mean of compensation for personal insecurities) was also weakly negatively associated with the perceived risk of posting pictures $(r=-.20, p=.008)$ and perceived risk of sharing activity information $(r=-.21, p=.006)$.

When looking at the number of risks mentioned in response to the open-ended question, there was a weak negative relationship between the number of risks mentioned and Facebook Addiction (those who spend a prolonged time on Facebook and have an inability to control it; $r=-.25, p<.001)$ and number of risks and Virtual Self $(r=-.18, p=.016)$.

Benefits. See Table 4 for correlations between perceived benefits and the PSAFU subscales. Of note is the positive association between the Virtual Self (characterizing those who felt Facebook is a realistic representation of oneself) and Compensatory Facebook use (describing the use of Facebook as a mean of compensation for personal insecurities) subscales on all types of benefits except sharing pictures with strangers. There was no relationship between the number of benefits mentioned and posting frequency $(r=.14$, $p=.056)$. Responses to the Virtual Self subscale correlated positively, but minimally with the number of benefits mentioned in response to the open-ended questions $(r=.25, p=.001)$.

Table 4

Associations Between Perceived Benefits and the Psychosocial Aspects of Facebook Use (PSAFU) Subscales

\begin{tabular}{|c|c|c|c|c|c|}
\hline PSAFU subscales & $\begin{array}{l}\text { Benefits } \\
\text { pictures }\end{array}$ & $\begin{array}{l}\text { Benefits sharing } \\
\text { activity info }\end{array}$ & $\begin{array}{c}\text { Benefits sharing } \\
\text { pictures with family }\end{array}$ & $\begin{array}{c}\text { Benefits sharing } \\
\text { pictures with friends }\end{array}$ & $\begin{array}{c}\text { Benefits sharing } \\
\text { pictures with strangers }\end{array}$ \\
\hline Virtual Self & $.405^{* *}$ & $.405^{* *}$ & $.341^{* *}$ & $.407^{* *}$ & .051 \\
\hline Facebook addiction & $.223^{* *}$ & $.221^{* *}$ & .170 & .181 & $.207^{*}$ \\
\hline Self-Presentation & .165 & .106 & .117 & .151 & .112 \\
\hline Compensatory Facebook use & $.322^{* *}$ & $.294^{* *}$ & $.271^{* *}$ & $.332 * *$ & .082 \\
\hline Socialization & $.214^{* *}$ & $.228^{* *}$ & .129 & .192 & .163 \\
\hline
\end{tabular}

* $p<0.002$ level. $* * p<.001$ level. 


\section{Discussion}

Our aim was to combine quantitative and qualitative insights to examine the Facebook sharenting behavior of mothers with young children, focusing on their understanding of risks and benefits and associated psychosocial factors. Results suggest that mothers chose to engage in sharenting despite being aware of a range of risks, which is similar to past results (e.g., Barnes \& Potter, 2021). Our study adds to these findings by showing that the number of risks mentioned was associated with reduced posting activity suggesting that knowledge does relate to parents' willingness to engage in protective behaviors. This was the case for general activity such as posting frequency but also sharenting specific activity such as sharing of children's photos. This indicates that the knowledge that sharenting is risky does not stop mothers from engaging in it. However, being aware of a variety of different risks can potentially make a difference to sharenting activity. This supports our second hypothesis. Our data also provide partial support for the privacy paradox (Barth \& De Jong, 2017), as a third of mothers shared sensitive information about their children while also recognizing the privacy concerns involved in sharenting.

Although participants weighted risks differently depending on the intended audience and type of information being shared, this did not seem to be associated with the choice of privacy setting. The majority had a "Friends" privacy setting, although most of the people in their list were not close friends or relatives and most participants were not aware of their friends' privacy setting. This approach is an issue because on Facebook information can be easily shared beyond the intended friend group, especially when tagging pictures (Yu et al., 2018). Furthermore, the privacy of information we share online is closely linked to those we are connected to (Humbert et al., 2019). The potential danger of believing such a privacy setting is protective against sharenting risks is evident in the negative experiences of a few participants who stated family and friends copied and shared child pictures without consent.

As opposed to our first hypothesis, one's own and others' previous negative experiences were not related to risk awareness which in turn was not associated with posting activity. This finding stands in contrast to earlier work which has reported that prior negative experiences increase privacy concerns and perceived risks (Bansal \& Gefen, 2010; Yang \& Liu, 2014). It could be that parents' positive experiences instead of negative ones drive their sharenting behavior, which future work should consider. It might also be that parents regard their own experiences as separate from the risks they are exposing their children to. In support of this we note that the most frequently mentioned negative experiences encountered by parents, namely, harassment and bullying were the least cited risks in relation to sharenting. In fact, while parents were aware of many important sharenting risks, they focused mostly on immediate dangers such as safeguarding issues particularly in relation to stranger danger. Statistics show that such fears might be unfounded, for example, children are more likely to be abducted by family members and acquaintances rather than strangers (Walsh et al., 2016). It might also be that for mothers of young children these risks are not viewed as immediate and are therefore not concerning. However, evidence suggests that some of the risks mentioned, such as cyberbullying, are potential immediate given that cyberbullying is present even in elementary school (Englander, 2012). Furthermore, sharing content with friends always has the potential to go viral and directly and immediately influence a child's life (Kopecky et al., 2020). Overall parents do not seem to consider their children's right to digital privacy or the potential for emotional harm and seem to largely ignore future consequences such as identity fraud. Overall, it appears that risk awareness is only associated with some aspects of sharenting, and some risks need to be further emphasized in this parent population. It might be that the open-ended nature of our questions led participants to respond by focusing on the most severe consequences. Nevertheless, we contend that these are likely the same factors considered when parents decide to share information.

Most risks significantly outweighed benefits, except when sharing pictures with family, where benefits outweighed the risks. This was in line with participants' responses to the open-ended questions where the majority mentioned sharing information with family and friends as the only benefit. Given these findings, one would expect stricter privacy settings. It could be that the perceived benefit of sharing information with family and friends is sufficient to counteract the perceived risks (Khan et al., 2014; Wang et al., 2016). In addition, there might be a discrepancy between how participants estimate risk and benefits severity and probability, for example, risks might be seen as rare but severe whereas benefits are frequent but mundane; future work should attempt to assess both probability and severity. Alternatively, it might be that participants underestimate or do not clearly articulate all benefits. For example, while research shows that receiving validation is a benefit that outweighs privacy concerns (Kumar \& Schoenebeck, 2015), this benefit was only minimally mentioned in our study.

Our analysis of psychosocial factors provides further insights. We found that the higher participants scored on the Virtual Self subscale, the less risks they mentioned and the less risky they perceived these to be. Similarly, they also mentioned more benefits and perceived all sharenting activities as more beneficial. This finding is interesting given that high scores on this subscale are characteristics of those open to experience and fearful of negative evaluation, that is, socially anxious (Bodroža \& Jovanović, 2016). Comparable results were obtained for those scoring high on the Compensatory Facebook use subscale which has been linked to traits indicating poor social adaptiveness (Bodroža \& Jovanović, 2016). These results are in line with the social compensation hypothesis which states that the internet primarily benefits those who feel uncomfortable communicating face to face (Weidman et al., 2012). Interestingly, those scoring high on the Socialization subscale, that is, characterized by higher sensation seeking (Bodroža \& Jovanović, 2016), tended to rate the perceived risks of sharing pictures with strangers as lower. On the other hand, those scoring highly on the Facebook Addiction subscale, known to be related to lower self-esteem, lower general self-efficacy, and introversion, attributed higher benefits to sharing pictures with strangers. These findings provide initial insights into the potential psychosocial factors linked to sharenting while also potentially explaining the motivation to engage in such behavior given that Facebook use can boost selfesteem (Gonzales \& Hancock, 2011). This highlights factors that are important when considering potential prevention and intervention strategies for dealing with sharenting. Future work should also attempt to measure psychological factors such as sensation seeking and self-esteem directly rather than through a proxy measure such as the PASFU. Psychosocial factors have been shown to be useful when considering interventions for other problematic behaviors such as excessive internet use (Zhang et al., 2016). 
Several limitations need to be noted. First, our study used selfreport measures of Facebook use, which have been shown to differ from more objective measures (Marasli et al., 2016). Second, our participants were highly educated, and this is positively associated with digital literacy (Park, 2013). However, these limitations are only likely to underestimate the extent of the issues presented in this article. Finally, our sampling method might affect the generalizability of results, as it could be that only mothers who are confident in their sharenting habits volunteered, and their experience might differ from others.

Overall, our findings provide a broader perspective of sharenting in mothers of young children. Results suggest that previous negative experiences are not associated with sharenting behavior. We also find that knowledge of risks is associated with some protective behaviors. Mothers balanced those risks with the ability to share child development with family and friends living afar. It is evident that sharenting offers mothers important benefits, thus interventions aimed at sharenting should not encourage parents to completely cease this practice. Instead, interventions should aim to provide parents with a better understanding of how sharing certain type of content can affect their child in the future and how to post responsibly in order to avoid potential pitfalls such as identity theft and emotional harm. Our findings also suggest that such practical approaches to sharenting would benefit from understanding how psychological factors drive sharenting behaviors.

\section{References}

Ammari, T., Kumar, P., Lampe, C., \& Schoenebeck, S. (2015, April). Managing children's online identities: How parents decide what to disclose about their children online [Conference session]. Proceedings of the 33rd Annual ACM Conference on Human Factors in Computing Systems, New York, NY, United States.

Bansal, G., \& Gefen, D. (2010). The impact of personal dispositions on information sensitivity, privacy concern and trust in disclosing health information online. Decision Support Systems, 49(2), 138-150. https:// doi.org/10.1016/j.dss.2010.01.010

Barnes, R., \& Potter, A. (2021). Sharenting and parents' digital literacy: an agenda for future research. Communication Research and Practice, 1(1), 6-20. https://doi.org/10.1080/22041451.2020.1847819

Barth, S., \& De Jong, M. D. (2017). The privacy paradox-Investigating discrepancies between expressed privacy concerns and actual online behavior-A systematic literature review. Telematics and Informatics, 34(7), 1038-1058. https://doi.org/10.1016/j.tele.2017.04.013

BBC News. (2015, December). Christmas card that shocked the web. https:// www.bbc.co.uk/news/blogs-trending-35128683

Bessant, C., Nottingham, E., \& Oswald, M. (2020, August 12). Sharenting in a socially distanced world: Parenting for a digital future. https://blogs.lse .ac.uk/parenting4digitalfuture/2020/08/12/sharenting-during-covid/

Bodroža, B., \& Jovanović, T. (2016). Validation of the new scale for measuring behaviors of Facebook users: Psycho-Social Aspects of Facebook Use (PSAFU). Computers in Human Behavior, 54, 425-435. https:// doi.org/10.1016/j.chb.2015.07.032

Briazu, R. A. (2021, July 21). Facebook sharenting in mothers of young children [Data set]. https://doi.org/10.17605/OSF.IO/HCMS7

Brosch, A. (2016). When the child is born into the Internet: Sharenting as a growing trend among parents on Facebook. The New Educational Review, 43(1), 225-235. https://doi.org/10.15804/tner.2016.43.1.19

Chalklen, C., \& Anderson, H. (2017). Mothering on Facebook: Exploring the privacy/openness paradox. Social Media + Society, 3(2), 1-10. https:// doi.org/10.1177/2056305117707187
Collins. (n.d.). Sharenting. https://www.collinsdictionary.com/dictionary/ english/sharenting

Coughlan, S. (2018, May). Sharenting puts young people at risk of online fraud. BBC News. https://www.bbc.co.uk/news/education-44153754

Davidson-Wall, N. (2018, April). "Mum, seriously!": Sharenting the new social trend with no opt-out [Paper presentation]. Debating Communities and Social Networks, Open Universities Australia conference, Perth, Australia. https://networkconference.netstudies.org/2018OUA/wp-conte nt/uploads/2018/04/Sharenting-the-new-social-trend-with-no-opt-out.pdf

Debatin, B., Lovejoy, J. P., Horn, A. K., \& Hughes, B. N. (2009). Facebook and online privacy: Attitudes, behaviors, and unintended consequences. Journal of Computer-Mediated Communication, 15(1), 83-108. https:// doi.org/10.1111/j.1083-6101.2009.01494.x

Duggan, M., Lenhart, A., Lampe, C., \& Ellison, N. B. (2015, July 16). Parents and social media. Pew Research Center. https://www.pewresea rch.org/internet/2015/07/16/parents-and-social-media/

Englander, E. (2012). Cyberbullying among 11,700 Elementary School Students, 2010-2012. In MARC research report (Paper 4, pp. 1-2). Bridgewater State University. http://vc.bridgew.edu/marc_reports/4

Erdfelder, E., Faul, F., \& Buchner, A. (1996). GPOWER: A general power analysis program. Behavior Research Methods, Instruments, \& Computers, 28(1), 1-11. https://doi.org/10.3758/BF03203630

Gibson, L., \& Hanson, V. L. (2013, April). Digital motherhood: How does technology help new mothers? [Conference session]. Proceedings of the SIGCHI Conference on Human Factors in Computing Systems, New York, NY, United States.

Gonzales, A. L., \& Hancock, J. T. (2011). Mirror, mirror on my Facebook wall: Effects of exposure to Facebook on self-esteem. Cyberpsychology, Behavior, and Social Networking, 14(1-2), 79-83. https://doi.org/10 .1089/cyber.2009.0411

Hadlington, L. (2017). Human factors in cybersecurity; examining the link between Internet addiction, impulsivity, attitudes towards cybersecurity, and risky cybersecurity behaviours. Heliyon, 3(7), Article e00346. https:// doi.org/10.1016/j.heliyon.2017.e00346

Hickey, G., \& Kipping, C. (1996). A multi-stage approach to the coding of data from open-ended questions. Nursing Research, 4(1), 81-91. https:// doi.org/10.7748/nr.4.1.81.s9

Humbert, M., Trubert, B., \& Huguenin, K. (2019). A survey on interdependent privacy. ACM Computing Surveys (CSUR), 52(6), 1-40. https:// doi.org/10.1145/3360498

Khan, G. F., Swar, B., \& Lee, S. K. (2014). Social media risks and benefits: A public sector perspective. Social Science Computer Review, 32(5), 606627. https://doi.org/10.1177/0894439314524701

Kopecky, K., Szotkowski, R., Aznar-Díaz, I., \& Romero-Rodríguez, J. M. (2020). The phenomenon of sharenting and its risks in the online environment. Experiences from Czech Republic and Spain. Children and Youth Services Review, 110, Article 104812. https://doi.org/10.1016/j .childyouth.2020.104812

Kumar, P., \& Schoenebeck, S. (2015). The modern day baby book. Enacting good mothering and stewarding on Facebook. In Proceedings of the CSCW '15, (pp. 1302-1312).

Magid, L. (2010, October). Study: 92\% of U.S. 2-year-olds have online record. CNET. https://www.cnet.com/tech/services-and-software/study92-of-u-s-2-year-olds-have-online-record/

Marasli, M., Suhendan, E., Yilmazturk, N. H., \& Cok, F. (2016). Parents' shares on social networking sites about their children: Sharenting. The Anthropologist, 24(2), 399-406. https://doi.org/10.1080/09720073.2016 .11892031

Minkus, T., Liu, K., \& Ross, K. W. (2015, May). Children seen but not heard: When parents compromise children's online privacy [Conference session]. Proceedings of the 24th International Conference on World Wide Web, New York, NY, United States. https://doi.org/10.1145/2736277 .2741124 
Moser, C., Chen, T., \& Schoenebeck, S. Y. (2017, May). Parents' and Children's preferences about parents sharing about children on social media [Conference session]. Proceedings of the 2017 CHI Conference on Human Factors in Computing Systems, New York, NY, United States. https://doi.org/10.1145/3025453.3025587

National Society for Prevention of Cruelty to Children. (2015). A parents' guide to being share aware. [Leaflet]. https://learning.nspcc.org.uk/media/ 1489/share-aware-parents-guide.pdf

Nottingham, E. (2019). Dad! Cut that part out!"Children"s rights to privacy in the age of 'generation tagged': Sharenting, digital kidnapping and the child micro-celebrity. In J. Murray, B. B. Swadener, \& K. Smith (Eds.), The Routledge international handbook of young children's rights (pp. 1-9). Routledge.

Office for National Statistics. (2018). Birth characteristics in England and Wales. https://www.ons.gov.uk/peoplepopulationandcommunity/birthsdea thsandmarriages/livebirths/bulletins/birthcharacteristicsinenglandandwa les/2018

Office for National Statistics. (2019a). Births by parents' characteristics. https://www.ons.gov.uk/peoplepopulationandcommunity/birthsdeathsa ndmarriages/livebirths/datasets/birthsbyparentscharacteristics

Office for National Statistics. (2019b). Internet access-households and individuals. https://www.ons.gov.uk/peoplepopulationandcommunity/ householdcharacteristics/homeinternetandsocialmediausage/bulletins/inte rnetaccesshouseholdsandindividuals/2019

Park, Y. J. (2013). Digital literacy and privacy behavior online. Communication Research, 40(2), 215-236. https://doi.org/10.1177/0093650211 418338

Plunkett, L. (2019). To stop sharenting \& other children's privacy harms, start playing: A blueprint for a new Protecting the Private Lives of Adolescents and Youth (PPLAY) act. Seton Hall Legislative Journal, 44(3), Article 2. https://scholarship.shu.edu/shlj/vol44/iss3/2

Ranzini, G., Newlands, G. E., \& Lutz, C. (2020). Sharenting, peer influence, and privacy concerns: A study on the instagram-sharing behaviors of parents in the United Kingdom. Social Media + Society, 6(4), 1-13. https://doi.org/10.1177/2056305120978376

Shmueli, B., \& Blecher-Prigat, A. (2010). Privacy for children. Columbia Human Rights Law Review, 42, Article 759. https://papers.ssrn.com/sol3/ papers.cfm?abstract_id=1746540

Siibak, A., \& Traks, K. (2019). The dark sides of sharenting. Catalan Journal of Communication \& Cultural Studies, 11(1), 115-121. https://doi.org/10 .1386/cjes.11.1.115_1

Sim, J., \& Wright, C. C. (2005). The kappa statistic in reliability studies: Use, interpretation, and sample size requirements. Physical Therapy, 85(3), 257-268. https://doi.org/10.1093/ptj/85.3.257

Steinberg, S. (2019, November 13). Growing up shared: Negotiating the risks and opportunities of 'sharenting', LSE parenting for a digital future blog. https://blogs.lse.ac.uk/parenting4digitalfuture/2019/11/13/growingup-shared-negotiating-the-risks-and-opportunities-of-sharenting/
Steinberg, S. B. (2016). Sharenting: Children's privacy in the age of social media. Emory Law Journal, 66, Article 839. https://scholarship.law.ufl .edu/cgi/viewcontent.cgi?article $=1796 \&$ context $=$ facultypub

Vasalou, A., Joinson, A. N., \& Courvoisier, D. (2010). Cultural differences, experience with social networks and the nature of "true commitment" in Facebook. International Journal of Human-Computer Studies, 68(10), 719-728. https://doi.org/10.1016/j.ijhcs.2010.06.002

Wagner, A., \& Gasche, L. A. (2018). Sharenting: Making decisions about other's privacy on social networking sites. Publications of Darmstadt Technical University, Institute for Business Studies (BWL), 90477.

Walsh, J. A., Krienert, J. L., \& Comens, C. L. (2016). Examining 19 years of officially reported child abduction incidents (1995-2013): Employing a four category typology of abduction. Criminal Justice Studies, 29(1), 2139. https://doi.org/10.1080/1478601X.2015.1129690

Wang, T., Duong, T. D., \& Chen, C. C. (2016). Intention to disclose personal information via mobile applications: A privacy calculus perspective. International Journal of Information Management, 36(4), 531-542. https://doi.org/10.1016/j.ijinfomgt.2016.03.003

Weber, E. U., Blais, A. R., \& Betz, N. E. (2002). A domain-specific risk-attitude scale: Measuring risk perceptions and risk behaviors. Journal of Behavioral Decision Making, 15(4), 263-290. https://doi.org/10.1002/bdm.414

Wegmann, E., \& Brand, M. (2019). A narrative overview about psychosocial characteristics as risk factors of a problematic social networks use. Current Addiction Reports, 6(4), 402-409. https://doi.org/10.1007/s40429-01900286-8

Weidman, A. C., Fernandez, K. C., Levinson, C. A., Augustine, A. A., Larsen, R. J., \& Rodebaugh, T. L. (2012). Compensatory internet use among individuals higher in social anxiety and its implications for wellbeing. Personality and Individual Differences, 53(3), 191-195. https:// doi.org/10.1016/j.paid.2012.03.003

Yang, H., \& Liu, H. (2014). Prior negative experience of online disclosure, privacy concerns, and regulatory support in Chinese social media. Chinese Journal of Communication, 7(1), 40-59. https://doi.org/10.1080/175 44750.2013 .816756

YouGov. (2020, Dec). Facebook. https://yougov.co.uk/topics/technology/ explore/social_network/Facebook

Youn, S. (2005). Teenagers' perceptions of online privacy and coping behaviors: A risk-benefit appraisal approach. Journal of Broadcasting \& Electronic Media, 49(1), 86-110. https://doi.org/10.1207/s15506878jobem4901_6

Yu, L., Motipalli, S. M., Lee, D., Liu, P., Xu, H., Liu, Q., Tan, J., \& Luo, B. (2018, June). My friend leaks my privacy: Modeling and analyzing privacy in social networks [Conference session]. In Proceedings of the 23nd ACM on Symposium on Access Control Models and Technologies, Indianapolis, Indiana, United States. https://doi.org/10.1145/3205977.3205981

Zhang, C., Brook, J. S., Leukefeld, C. G., \& Brook, D. W. (2016). Longitudinal psychosocial factors related to symptoms of Internet addiction among adults in early midlife. Addictive Behaviors, 62, 65-72. https:// doi.org/10.1016/j.addbeh.2016.06.019 


\section{Appendix A}

\section{About Your Social Media Usage}

How many Facebook friends do you have? If unsure, please estimate:

To the best of your knowledge, who can see your Facebook page and what you share? (i.e., privacy setting).

\begin{tabular}{llll}
\hline Public & Friends of friends & Friends & Custom audience \\
\hline
\end{tabular}

To the best of your knowledge, who can see your Friends' Facebook pages and what they share? (i.e., privacy setting).

\begin{tabular}{llll}
\hline Public & Friends of friends & Friends & Custom audience \\
\hline
\end{tabular}

How many of your Facebook friends have you known Face to Face?

\begin{tabular}{lllll}
\hline None & Less than half & Half & More than half \\
\hline
\end{tabular}

How many of your Facebook Friends are family/relatives?

\begin{tabular}{lllll}
\hline None & Less than half & Half & More than half \\
\hline
\end{tabular}

How many of your Facebook friends do you communicate with outside of Facebook?

\begin{tabular}{lllll}
\hline None & Less than half & Half & More than half & All \\
\hline
\end{tabular}

How many times do you post on Facebook per week? Photos, Videos, Statuses, etc.

\begin{tabular}{lllll}
\hline 0 & $1-5$ & $6-10$ & $11-15$ & $15+$ \\
\hline
\end{tabular}

Prior to the birth of your youngest child, how often did you post on Facebook?

\begin{tabular}{lllll}
\hline Much less & Less & Same & More \\
\hline
\end{tabular}

Since the birth of your youngest child, how often have you used Facebook?

\begin{tabular}{lcll}
\hline Much less & Sess & More & Much more \\
\hline & & & \\
Have you ever uploaded photos of your child/children to Facebook? Yes/No & & \\
If yes, how many times per week do you post photos of your children to Facebook? & & $11-15$ \\
\hline 0 & $6-10$ & $15+$ \\
\hline
\end{tabular}

How likely are your Friends to comment on/acknowledge the photos you upload of your child, as compared to other photos (photos of yourself, your partner, etc)?

\begin{tabular}{llll}
\hline Much less & Less & Same & More
\end{tabular}

What kind of information do you share about your children on social media?

\begin{tabular}{llll}
\hline Special days & Health issues & Social activities done with children & Play activities \\
General recommendations on products & Sports/Arts activities & Educational Issues & Other \\
\hline
\end{tabular}

Aside from Facebook, do you share information about your child/children on any other media platforms? Circle all that apply.

\begin{tabular}{llllll}
\hline Twitter & Instagram & MySpace & Blogs & Snapchat & Others \\
\hline
\end{tabular}




\section{Appendix B}

On a scale of 1 (Very low risk) to 7 (Very high risk) How risky is it to;

- Post pictures on social networking sites such as Facebook or Instagram

- Share information about your children's activities on social networking sites

- Share pictures of your children on social media such as Facebook and Instagram with family members

- Share pictures of your children on social media such as Facebook and Instagram with friends

- Share pictures of your children on social media such as Facebook and Instagram with strangers

In your opinion, what could be the risks of sharing information or pictures of your children?

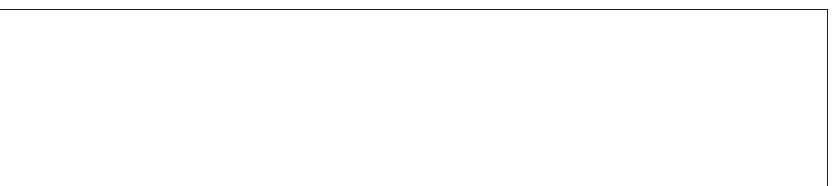

On a scale of 1 (Very low benefit) to 7 (Very high benefit), how beneficial is it to;

- Post pictures on social networking sites such as Facebook or Instagram

- Share information about your children's activities on social networking sites

- Share pictures of your children on social media such as Facebook and Instagram with Family members

- Share pictures of your children on social media such as Facebook and Instagram with friends

- Share pictures of your children on social media such as Facebook and Instagram with strangers

In your opinion, what could be the benefits of sharing information or pictures of your children?

Received March 16, 2021

Revision received August 3, 2021

Accepted August 3, 2021 